\title{
Gastrointestinal/Pancreatic Hormone Concentrations in the Portal Venous System of Nine Patients With Organic Hyperinsulinism
}

\author{
B. Glaser, G. Valtysson, S. S. Fajans, A. I. Vinik, K. Cho, and N. Thompson
}

Percutaneous transhepatic sampling of blood in the portal venous system (TPVS) was used to: (1) localize hormone secreting tumors and help in differentiating tumors from diffuse disease (nesideoblastosis and hyperplasia with adenomata) in 9 patients with fasting hypoglycemia and hyperinsulinism, and (2) study the concentration and distribution of the immunoreactive peptides: insulin (IRI), gastrin (IG), glucagon (IRG), pancreatic polypeptide (hPP), and somatostatin (SRIF-LI), in the venous drainage of the uninvolved portion of the pancreas and GI tract. Localized elevations of IRI (64-920 $\mu \mathrm{U} / \mathrm{ml}$ ) predicted tumor localization in 6 patients with single tumors that were not demonstrable angiographically. In one patient with nesideoblastosis and another with islet cell hyperplasia with adenoma, elevated IRI concentrations at multiple locations suggested a diffuse or multicentric process. Elevations of SRIF-LI in the same region as IRI elevations in one patient and of IRG in another patient suggested that these tumor produced two hormones. Some problems in the interpretation of portal venous insulin concentrations are discussed. The locations of maximum portal venous system plasma concentrations and portal-arterial gradients (mean $\pm \mathrm{SE} \mathrm{pg} / \mathrm{ml}$ ) in five patients with small single insulinomas were: IG, gastrocolic trunk (126 $\pm 27,46 \pm 22)$; IRG, proximal splenic vein $(130 \pm 30,47 \pm 13)$ and gastrocolic trunk (131 \pm 23 , $60 \pm 13)$; hPP, portal vein (164 $\pm 48,49 \pm 22)$; SRIF-LI, superior mesenteric vein $(186 \pm 50,57 \pm 20)$ and gastrocolic trunk (178 $\pm 59,55 \pm 21)$. It is concluded; (1) TPVS can be used successfully to localize single insulin-secreting tumors of the pancreas and to help distinguish them from diffuse disease but problems in such differentiation do occur, (2) circulating SRIF-LI and IRG are derived from both the pancreas and the gut, IG predominantly from the proximal gut and hPP from the head of the pancreas, and (3) The data provide new information for the interpretation of portal insulin concentrations in patients with organic hyperinsulinism and of hormone concentrations for localization of peptide-producing tumors of the pancreas other than insulinomas.

\section{$\mathbf{H}$} ORMONE-SECRETING tumors of the gastrointestinal tract occur predominantly in the pancreas, and rarely in and around the duodenum and stomach. When these tumors are small, localization by angiography ${ }^{1,2,3}$ may fail. Abdominal ultrasound ${ }^{4}$ and computed tomography (CT) have proved of limited value. Insulinomas, for example, are not localized by these methods in $34 \%$ of cases. ${ }^{5}$ Ingemansson, et al. ${ }^{6}$ first demonstrated the feasibility of percutaneous transhepatic sampling of blood from the portal venous system (TPVS) with identification of high IRI concentrations in the venous effluent at the site of a tumor. This technique has been employed by several groups in the successful localization of insulinomas ${ }^{6-10}$ and there have been three cases reported from the United States. 8.9

Aside from insulinomas, tumors secreting gastrin, ${ }^{11}$ glucagon, ${ }^{12}$ somatostatin, ${ }^{13.19}$ human pancreatic polypeptide (hPP), ${ }^{20}$ vasoactive intestinal polypeptide (VIP), ${ }^{21.22}$ mixed endocrine tumors, ${ }^{23}$ and diffuse islet cell adenomatosis ${ }^{24}$ have all been described as producing clinical syndromes. Gastrinomas, ${ }^{25,26}$ glucagonomas ${ }^{27}$ and islet cell hyperplasia ${ }^{28}$ have been localized by hormone concentrations in the portal venous effluent. There has been no report of the concentration of hormone levels in the venous effluent of somatostatin-secreting or mixed endocrine tumors.

The various hormone-secreting cells are not evenly distributed throughout the pancreas. ${ }^{29,30,31}$ This nonhomogeneity of hormone content, if reflected in portal venous hormone concentrations, may complicate inter- pretation of data obtained in patients with gastrin, glucagon, somatostatin or pancreatic polypeptide secreiing tumors. For this reason it is important to establish the "normal" pattern of hormone secretion into the gut and pancreatic venous drainage

We report here localization of tumors in five patients with single insulinomas; recognition of multicentric or diffuse disease in one patient with nesideoblastosis and one with islet hyperplasia and adenoma; and the diagnosis of a mixed insulinoma/somatostatinoma and insulinoma/glucagonoma. We have also established the profile of hormone concentrations of gastrin, "pancreatic" glucagon, hPP and somatostatin-like immunoreactivity (SRIF-LI) in the portal venous system, and the portal-systemic concentration gradients of these peptides in humans.

From the Departments of Internal Medicine (Division of Endocrinologv and Metabolism and the Metabolism Research Unit), Surgery, and Radiology. The University of Michigan, Ann Arbor. Michigan.

Supported in part by U.S. Public Health Service grants AM02244, AM-00888. T32 AM-07245, 5M01 RR-42 and 5-P60AM 20572; and the Upjohn Co., Kalamazoo, Michigan and Pfizer. Inc., New York, New York.

Received for publication December 30, 1980.

Address reprint requests to Stefan S. Fajans, M.D., Professor of Internal Medicine, Head, Division of Endocrinology and Metabolism. C7009 Outpatient Building. Box 002. Ann Arbor, Michigan 48109 .

c 1981 by Grune \& Stratton, Inc. 
Table 1. Clinical Details of 9 Patients with Organic Hyperinsulinism

\begin{tabular}{|c|c|c|c|c|c|c|c|c|c|c|c|c|}
\hline \multirow[b]{2}{*}{ Patient } & \multirow[b]{2}{*}{ Age } & \multirow[b]{2}{*}{ Sex } & \multirow[b]{2}{*}{$\begin{array}{l}\text { Height } \\
\text { (inches) }\end{array}$} & \multirow[b]{2}{*}{$\begin{array}{l}\text { Weight } \\
\text { (pounds) }\end{array}$} & \multirow[b]{2}{*}{$\begin{array}{c}\text { Duration of } \\
\text { Symptoms } \\
\text { (yr) }\end{array}$} & \multicolumn{5}{|c|}{ Prolonged Fast } & \multirow[b]{2}{*}{$\begin{array}{c}\text { Fasting } \\
\text { Proinsulin } \\
(\%) \S\end{array}$} & \multirow[b]{2}{*}{$\begin{array}{l}\text { Operative } \\
\text { Findings }\end{array}$} \\
\hline & & & & & & $\begin{array}{c}\text { Hours to } \\
\text { Hypoglycemia }\end{array}$ & $\begin{array}{c}\text { Glucose } \\
\text { Nadir } \\
(\mathrm{mg} \%)\end{array}$ & $\begin{array}{c}\text { IRI } \\
\langle\mu \mathrm{U} / \mathrm{ml}|)\end{array}$ & $1 / G+$ & $\mathrm{Al} / \mathrm{G} \ddagger$ & & \\
\hline A. EV & 26 & $M$ & 68 & 214 & 2.5 & 16.5 & 42 & 22 & 0.5 & 236 & 62 & 1 \\
\hline B. DS & 40 & $F$ & 65 & 179 & 7 & 15 & 42 & 36 & 0.86 & 300 & 22 & 1 \\
\hline c. $\mathrm{NH}$ & 33 & $M$ & 72 & 189 & 10 & 12 & 41 & 14 & 0.34 & 127 & 53 & 1 \\
\hline E. $A B$ & 60 & $M$ & 70 & 191 & 2 & 21 & 44 & 30 & 0.69 & 214 & 44 & 1 \\
\hline F. ASa & 30 & $M$ & 68 & 211 & 2 & 18 & 41 & 53 & 1.29 & 481 & 67 & 1 \\
\hline $\begin{array}{l}\text { G. AW } \\
\text { (see below) }\end{array}$ & 20 & $\mathbf{M}$ & 63 & 165 & 19 & 20.5 & 40 & 23 & 0.58 & 233 & 23 & 2 \\
\hline H. AS & 58 & $F$ & 66 & 233 & 1 & 45 & 43 & 17 & 0.4 & 131 & 31 & 3 \\
\hline I. SP & 23 & $\mathrm{~F}$ & 60 & 103 & 10 & 66 & 37 & 38 & 1.03 & 540 & 66 & 1 \\
\hline
\end{tabular}

1 = single adenoma.

2 = nesideoblastosis.

3 = macroadenoma + islet hyperplasia.

None of the patients had a personal or family history of multiple endocrine neoplasia.

AW had symptoms from age 1-17 yr which were thought to be due to a convulsive disorder; biochemical hypoglycemia was recognized for the first time at age $17 \mathrm{yr}$. There was some change in symptomatology between ages 17-20 yr; it was entertained that he may have developed fasting hypoglycemia during this period of time. Because the confusing nature of the history and intermittent hyperinsulinism, the patient was referred for differential diagnosis and treatment.

* Symptomatic hypoglycemia.

$+\mathrm{J} / \mathrm{G}=$ insulin $\mu \mathrm{U} / \mathrm{ml} / \mathrm{Giucose} \mathrm{mg} / \mathrm{d} l|\mathrm{nl}=<0.3\rangle$.

$\ddagger A \mid / G=$ Amended $\mathrm{V} / \mathrm{G}=$ Insulin $\mathrm{mg} / \mathrm{dl} /$ Glucose $\mathrm{mg} / \mathrm{dl}-30(\mathrm{nl} \leq 50)(32)$.

$\S$ Normal Proinsulin $<22 \%$.

HOperative findings.

\section{MATERIALS AND METHODS}

\section{Patients}

The clinical details of the 9 patients are given in Table 1. All had symptomatic hypoglycemia due to organic hyperinsulinism diagnosed before transhepatic venous sampling by; (1) the presence of inappropriately high plasma insulin concentrations for the prevailing glucose concentration, including an abnormal plasma insulin/ glucose ratio or "amended ratio",;2 and (2) a plasma proinsulin content of $>22 \%$ of total insulin immunoreactivity in the fasting state of all patients except D.S. ${ }^{33}$ All underwent pancreatic angiography which included utilization of subselective catheterization technique and pharmacoangiography. Additional subtraction and magnification techniques were used to enhance tumor visibility. In addition to selective celiac and superior mesenteric angiography, superselective injections of splenic, gastroduodenal, dorsal pancreatic, pancreatica magna and inferior pancreaticoduodenal arteries were necessary to adequately visualize the entire intrapancreatic arterial system and produce a pancreatic parenchymal stain. A tumor was demonstrable angiographically in 2 patients (A.S. \& S.P.)

\section{Catheterization Procedure}

Before transhepatic portal vein catheterization, the venous phase of the celiac and superior mesenteric angiograms were reviewed to locate and establish the patency of the portal vein. Each subject received heavy sedation and analgesia with demerol, valium and chlorpromazine. Under local anesthesia, a 19-gauge Tefion catheter was introduced in the mid-axillary line and with the patient holding his breath the catheter was advanced in the horizontal plane towards the hepatic hilum. The placement of the tip of the catheter in a portal venous radicle was confirmed by radio-opaque dye injection. The catheter was then advanced into portal, splenic and superior mesenteric veins over a curved guide wire. Portograms were obtained with injection of contrast medium into the distal splenic and superior mesenteric veins, respectively. Using these portograms to identify sites along the venous drainage (Fig. 1), blood samples were obtained along the superior mesenteric, splenic and portal veins at $1.5-2 \mathrm{~cm}$ intervals. Additional samples were obtained from the dorsal pancreatic, gastrocolic, coronary, and superior pancreatico-duodenal veins whenever possible. A catheter was also placed in the celiac artery via a percutaneous transfemoral approach and arterial blood samples were collected simultaneously with each venous sample. After the procedure was completed, the transhepatic venous catheter was withdrawn to near the hepatic capsule and the catheter track was filled with one or two pieces of Gelfoam to prevent hemorrhage or leakage of bile.

In all patients except one (N.H.), glucose concentrations remained stable throughout the procedure. In this patient, because of the presence of early morning hypoglycemia despite adequate night time feeding, a constant intravenous infusion of glucose was maintained during the procedure. Plasma glucose concentrations were elevated in this patient throughout the procedure.

\section{Blood Sampling and Storage}

Each blood sample $(7-8 \mathrm{ml})$ was immediately aliquoted into two heparin-coated tubes, one containing Trasylol (Aprotinin, Mobay) $1000 \mathrm{KIU} / \mathrm{ml}$ whole blood. Both tubes were gently mixed and immediately placed on ice. Plasma was separated in a refrigerated centrifuge within 60 mimutes. The plasma containing Trasylol was aliquoted into two plastic tubes for SRIF-LI assay while the remaining plasma was aliquoted into three tubes for remaining hormone and glucose assays. All samples were frozen for later assay. Care was taken to avoid thawing and refreezing of samples before glucagon and SRIF-LI determinations. 

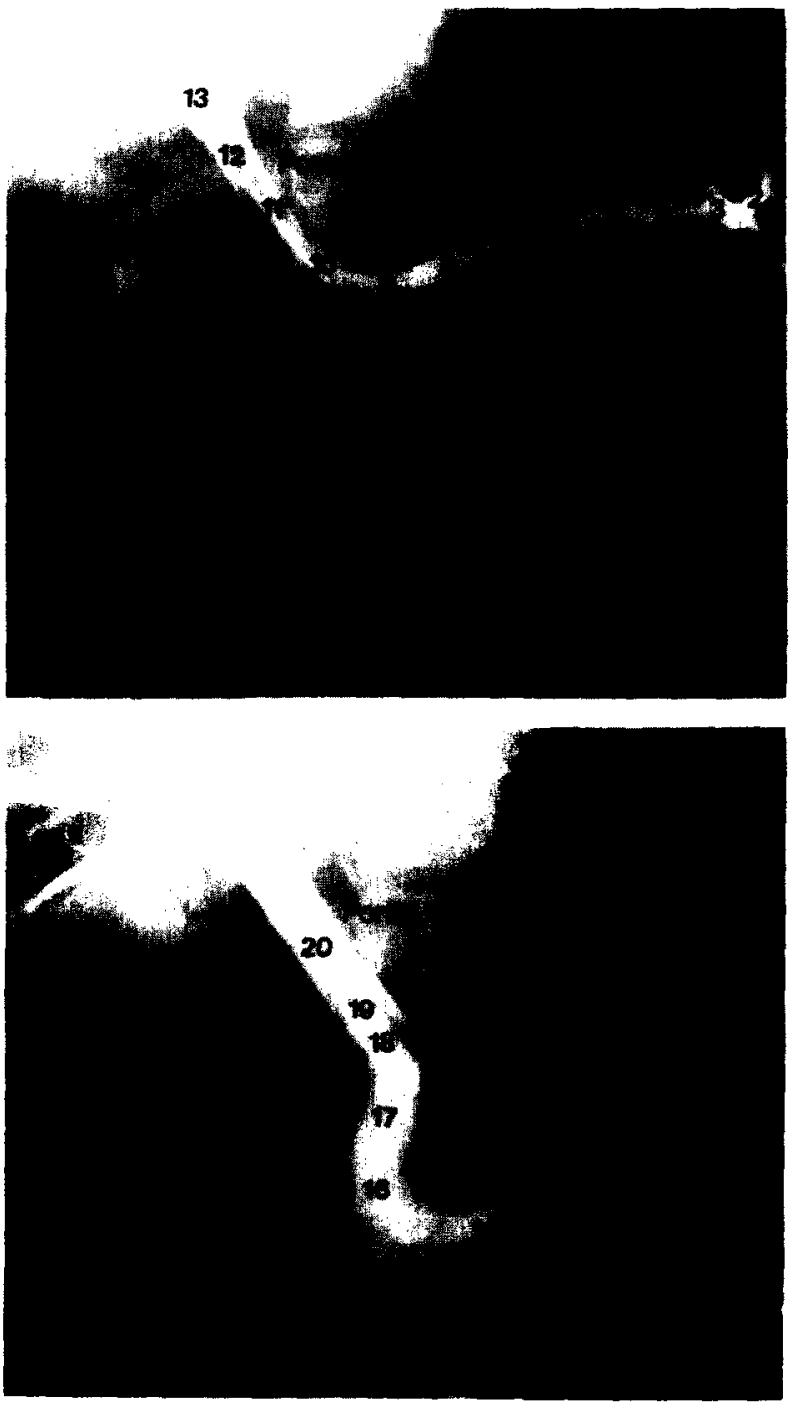

Fig. 1. Injections of splenic and superior mesenteric veins with superimposed numbers showing location of blood sampling.

\section{HORMONE ASSAYS}

\section{Insulin}

I mmunoreactive insulin was measured by a double-antibody RIA which detects total insulin in plasma. ${ }^{34}$ The least detection limit was $0.15 \mu \mathrm{U} / \mathrm{tube}$, the intraassay variation was $3.2 \%$. The mean $\pm \mathrm{SE}$ concentration of insulin in peripheral venous plasma from fasting healthy nonobese subjects was $10.9 \pm 1.4 \mu \mathrm{U} / \mathrm{ml}$.

\section{Gastrin}

Immunoreactive gastrins were measured by RIA using ion exchange resin to separate the bound from free-labeled peptide. ${ }^{35}$ The antisera (G2 Cape Town, South Africa) recognizes all forms of gastrin. Synthetic heptadecapeptide 15-Leu gastrin was used for labeling with ${ }^{125} I$ and 15 -Met-gastrin as standard. The least detection limit was $0.16 \mathrm{pg} /$ tube, the intraassay variation was $4 \%$. The mean \pm SE concentration of gastrin in peripheral venous plasma of fasting healthy subjects was $45 \pm 9 \mathrm{pg} / \mathrm{ml}$.

\section{Glucagon}

Plasma levels of "pancreatic" glucagon (IRG) were measured using a double antibody RIA. ${ }^{36}$ The antiserum, G9-1 (Ann Arbor, Michigan) used in the assay detects the $(-$-terminal region of the glucagon molecule and has negligible $(2 \%-5 \%)$ cross-reactivity with intestinal glucagon-like material (GL1). It does, however, detect glucagon of varying molecular weights. The mean : SE plasma concentration of glucagon in fasting young adults was $64 \pm 8 \mathrm{pg} / \mathrm{ml}$. The least detection limit was $3.4 \mathrm{pg} / \mathrm{tube}$, the intraassay variation was $4.1 \%$

\section{Pancreatic Polypeptide}

Human pancreatic polypeptide was measured by double antibody RIA $^{37}$ using ${ }^{125}$ I-labeled bPP as tracer (Eli Lilly Co. lot no. 615D63-188-9), antiserum to hPP (Eli Lilly lot no. 615-1054B-248-19) and hPP (Eli Lilly \& Co. lot no. 615-1054B-200) as standard. The least detection limit was $2.5 \mathrm{pg} /$ tube, the intraassay variation was $12 \%$. The levels of peripheral venous plasma hPP (mean \pm SD) in fasting healthy subjects by decades, $3-7$ ( 263 subjects) were: $54 \pm$ $28,115 \pm 98,165 \pm 159,181 \pm 166,207 \pm 129 \mathrm{pg} / \mathrm{ml}$.

\section{Somatostatin}

Immunoreactive somatostatin (SRIF-LI) was measured by RIA using charcoal to separate the bound and free-labeled hormone. ${ }^{38}$ The antiserum (1374 Cape Town, South Africa) recognizes the C-terminal 6-11 aminoacid region. Tyr'-SRIF (courtesy of $\mathbf{J}$. Rivier, Salk Institute, LaJolla, California) was labeled with ${ }^{125}$ I to a specific activity of $1000 \mu \mathrm{Ci} / \mu \mathrm{g}$ and repurified by cation exchange chromatography using Whatman $\mathrm{CM}_{52}$ cellulose and an ammonium acetate gradient of $0.05-500 \mathrm{mM}$. Plasma samples were not extracted. The assay was carried out at pH 5.3 in $50 \mathrm{mM}$ ammonium acetate buffer containing $0.05 \%$ EDTA. Under these conditions, incubation of tracer in plasma for 48 hours resulted in less than $2 \%$ damage, adsorption to charcoal was $92 \%$ and nonspecific adsorption to plasma proteins was $2 \%$. SR $1 \mathrm{H}-\mathrm{LI}$ added to plasma was completely recovered and serial dilutions of plasma were parallel to the synthetic standard. The least detection limit was 1.75 $\mathrm{pg} /$ tube, the intraassay variation was $12 \%$. SRIF-LI concentrations in unextracted peripheral venous plasma of fasted healthy subjects ranged between $50-300 \mathrm{pg} / \mathrm{ml}$.

\section{Glucose}

Plasma glucose was measured by the procedure of Worthington Biochemical Company based on the coupled-enzyme method of Slein, ${ }^{39}$ using hexokinase and glucose-6-phosphate dehydrogenase, with modifications by Bondar and Mead. ${ }^{* 0}$

\section{RESULTS}

In 6 of the 9 patients studied, pancreatic angiography, abdominal CT scan and ultrasound failed to identify a tumor where a single tumor was later found at operation; one in the head, three in the neck, one in the body, and one in the tail of the pancreas. All six of these tumors were localized by the maximum hormone level in the portal venous system (Table $2 \mathrm{~A}-\mathrm{E}$ ). Figure $2 \mathrm{~A}-\mathrm{E}$ is a schematic representation of the sites of each tumor and the concentrations of insulin in the portal venous system in 5 of these patients. A sixth patient, A.Sa., had a single tumor in the neck of the 
Table 2. Insulin (IRI) Concentrations and Gradients $(\mu \mathrm{U} / \mathrm{mI})$ in Patients With Single Insulin-Producing Islet Cell Tumors

\begin{tabular}{|c|c|c|c|c|c|c|c|c|}
\hline $\begin{array}{c}\text { Patient } \\
\text { Name }\end{array}$ & $\begin{array}{l}\text { Tumor } \\
\text { Site }\end{array}$ & $\begin{array}{l}\text { Tumor } \\
\text { Size } \\
(\mathrm{cm})\end{array}$ & $\begin{array}{c}\text { (1) } \\
\text { Max IRI } \\
\text { Value } \\
\text { in PVS* }\end{array}$ & $\begin{array}{c}(2) \\
\text { Simultan } \\
\text { Arterial } \\
\mid \mathbf{I R |}\end{array}$ & $\begin{array}{c}(3) \\
\text { Gradient } \\
(P-A) \dagger \\
(1)-(2)\end{array}$ & $\begin{array}{c}(4) \\
\bar{x} \pm \text { SE IRI } \\
\text { Uninvolved } \\
\text { (PVS)* }\end{array}$ & $\begin{array}{c}(5) \\
\tilde{\mathrm{x}} \pm \mathrm{SE} \text { IRI } \\
\text { Simultaneous } \\
\text { Arterial }\end{array}$ & $\begin{array}{c}(6) \\
\text { Gradient } \\
(P-A) \dagger \\
(4)-(5)\end{array}$ \\
\hline A. E.V. †t & Head & $2 \times 1$ & 64 & 25 & 39 & $20.1 \pm 1$ & $22 \pm 1.1$ & -2 \\
\hline B. D.S. $† \dagger$ & Neck & $0.8 \times 1.0$ & 941 & 43 & 898 & $36 \pm 2.5$ & $44 \pm 1.5$ & -8 \\
\hline C. N.H. † $^{-}$ & Body & $1 \times 1$ & 690 & 22 & 668 & $37 \pm 5$ & $29 \pm 1$ & $+8 \S$ \\
\hline D. R.S. $† \dagger$ & Neck & $2.5 \times 2$ & 240 & 69 & 171 & $55 \pm 1$ & $63 \pm 1.4$ & -8 \\
\hline E. A.B. $† \dagger$ & Tail & $2 \times 3$ & 292 & 41 & 251 & $30.6 \pm 2.7$ & $38 \pm 2.5$ & -7 \\
\hline F. A.Sa. $† \dagger$ & Neck & $1.9 \times 1.7$ & 863 & 80 & 783 & $61 \pm 4.2$ & $69 \pm 3.6$ & -8.2 \\
\hline G. S.P. & Head & $7 \times 5$ & 73 & 21 & 52 & $16.5 \pm 1$ & $18 \pm 1$ & -1.5 \\
\hline $\bar{x}$ & & & 452 & 43 & 409 & 36.6 & 40 & -3.8 \\
\hline S.E. & & & 140 & 9 & 137 & 6.3 & 7.4 & -2.2 \\
\hline
\end{tabular}

*PVS = portal venous system

†Portal venous system - simultaneous celiac arterial insulin concentration.

$\uparrow †$ Abdominal angiogram, CAT and ultrasound negative.

§This patient received glucose during the procedure which may explain the positive IRI gradient.

A
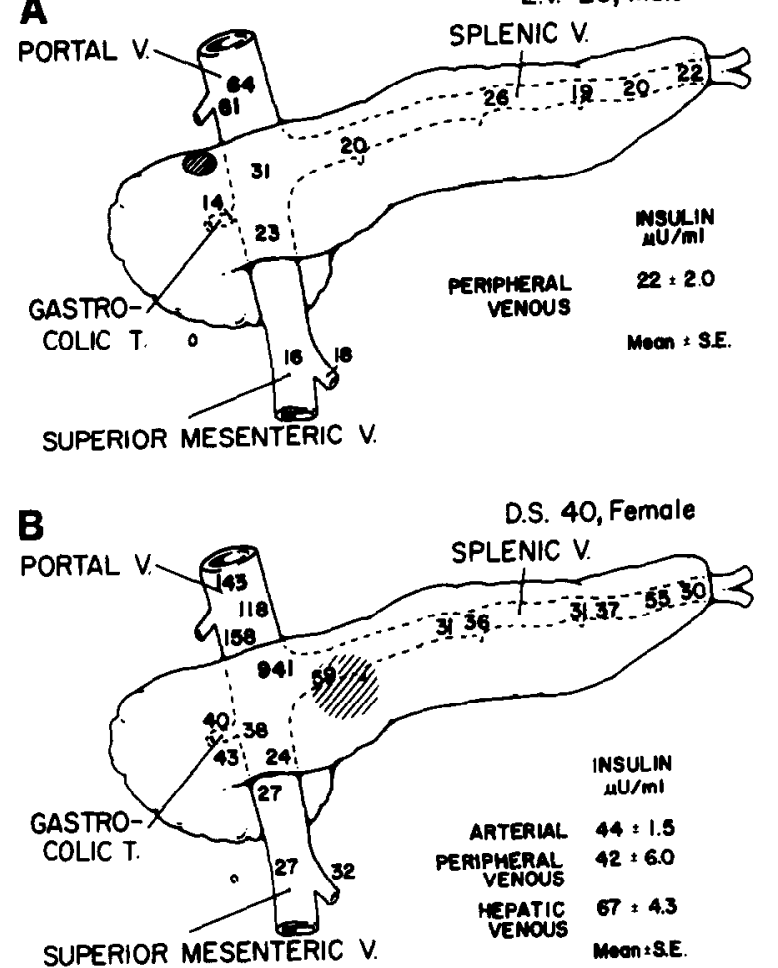

C

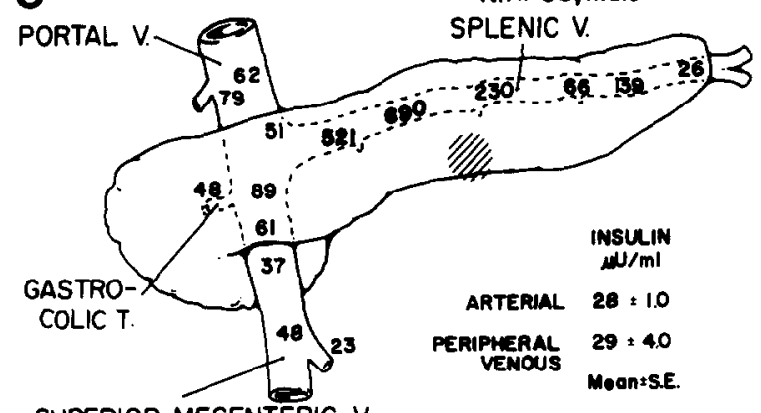

D

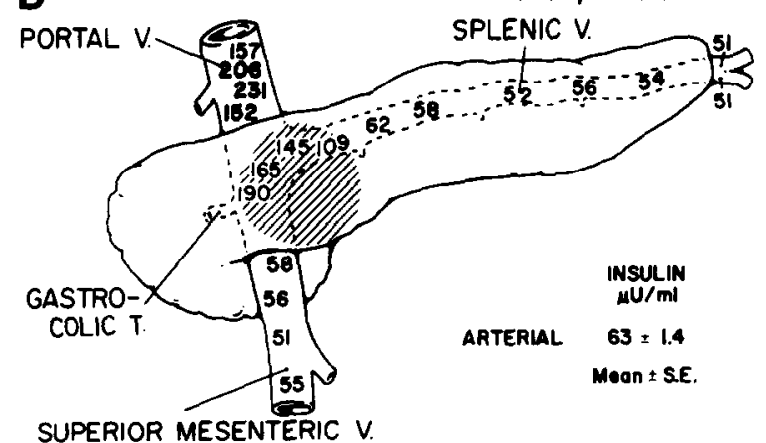

$\mathbf{E}$

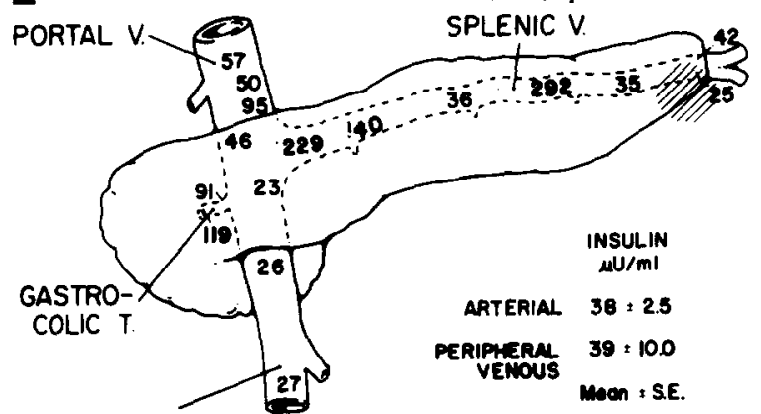

SUPERIOR MESENTERIC $V$.
Fig. 2. Schematic representations of pancreas and portalvenous system in 5 patients with localized insulin-producing tumors not demonstrated by angiograph. Plasma insulin levels are shown throughout the portal system along with location of the tumor found at surgery. The apparent inconsistent findings in Fig. 2E (A.B.) are explained partially in Fig. 6. 
pancreas (Fig. 3). Elevated glucagon concentrations in the portal venous system (Fig. 3B) adjacent to the elevated insulin concentrations suggested glucagon as well as insulin production by the tumor. The maximum IRI concentrations ranged from 64-94I $\mu \mathrm{U} / \mathrm{ml}$ with a mean \pm SE of $452 \pm 140 \mu \mathrm{U} / \mathrm{ml}$ (Table 2). The mean $\pm \mathrm{SE}$ of insulin concentrations in samples drawn simultaneously from the celiac artery was $43 \pm 9$ $\mu \mathrm{U} / \mathrm{ml}$ and that in the veins draining the uninvolved pancreas was $36.6 \pm 6.3 \mu \mathrm{U} / \mathrm{ml}$. The gradicnt (tumor site--simultaneous arterial) ranged from 39-898 $\mu \mathrm{U} /$ $\mathrm{ml}$ with a mean $\pm \mathrm{SE}$ of $409 \pm 137 \mu \mathrm{U} / \mathrm{ml}$.

In a seventh patient (A.W., Table IG) also with negative preoperative angiography elevated insulin concentrations were found in the distal and midsplenic vein, proximal pancreatic vein (highest level) and the portal vein, suggesting multiple areas of insulin hypersecretion (Fig. 4A). A tumor was not found at operation and a $95 \%$ pancreatectomy performed. Extra-islet endocrine cells which stained immunochemically for insulin were seen associated with pancreatic ducts, confirming the diagnosis of nesideoblastosis. Extra-

A

INSULIN

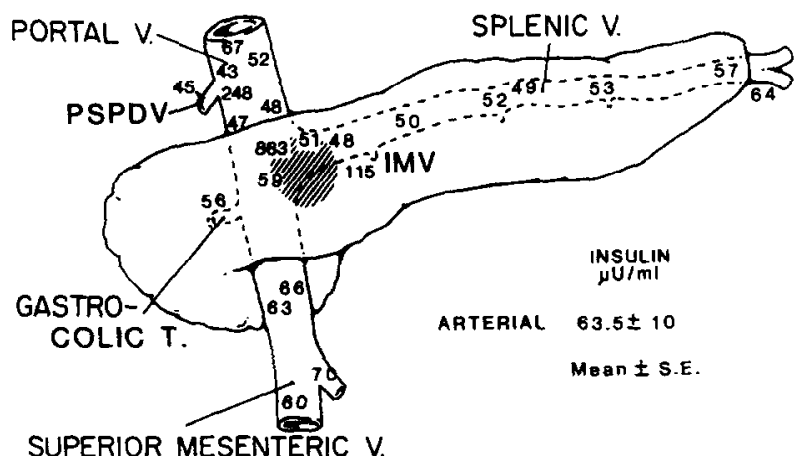

B

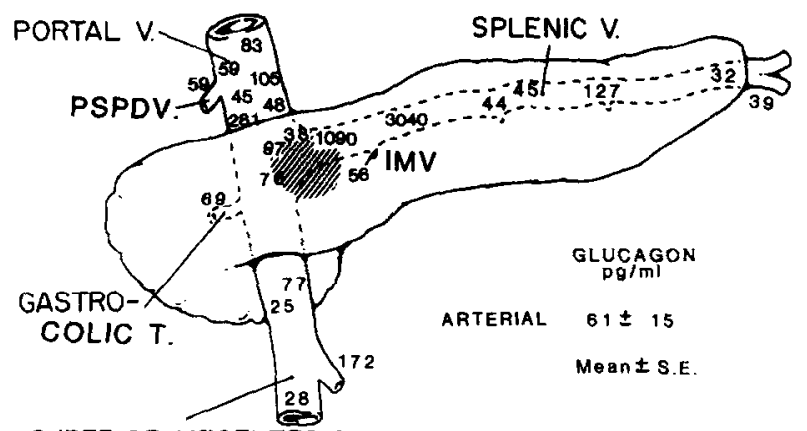

SUPERIOR MESENTERIC $V$.

Fig. 3. Schematic representation of pancreas and portal venous system in a 30-yr-old male (A.Sa.) with fasting hypoglycemia. Elevated concentrations of both IRI (A) and IRG (B) from the venous drainage of the neck of the pancreas suggests that the tumor produced both hormones.
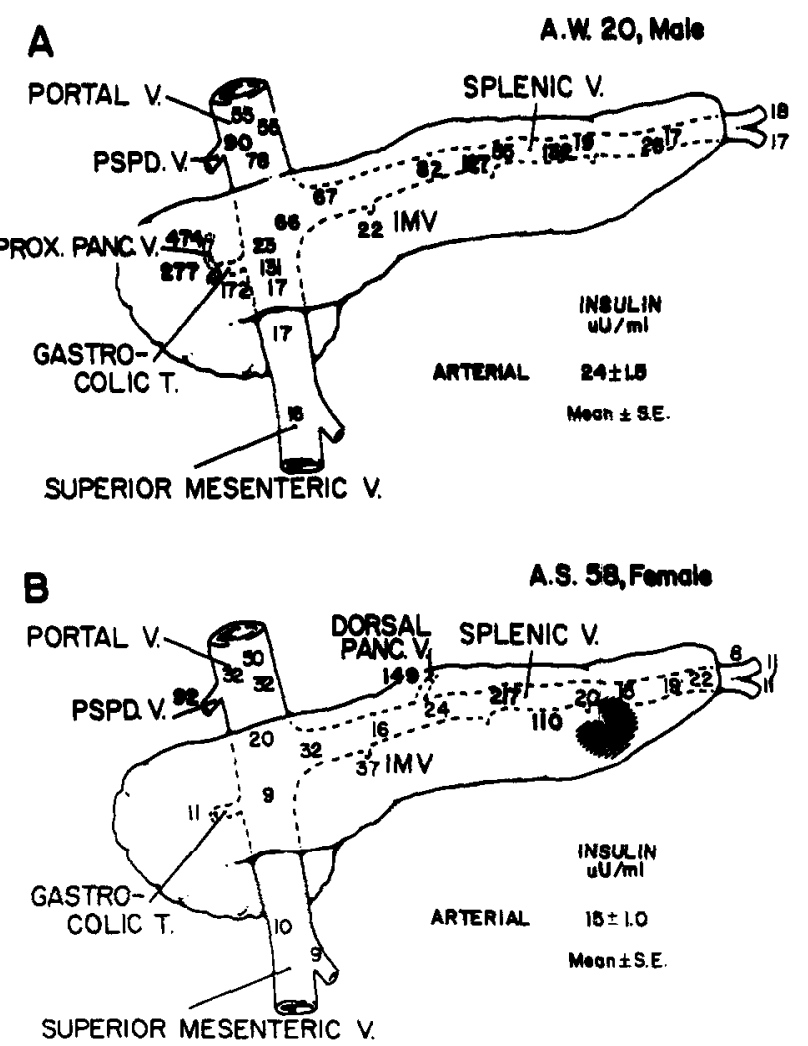

Fig. 4. Schematic representation of the pancreas and portalvenous system in 2 patients with diffuse or multifocal excessive insulin production (A) nesideoblastosis (B) islet hyperplasia with macroadenoma. Plasma insulin levels are shown throughout the portal system.

islet insulin-containing ductal cells and large, irregularly-shaped islet cells as well as normal-appearing islets were particularly frequent in the head of the pancreas corroborating the findings at TPVS that the most marked elevation of IRI was in the venous drainage of the head of the pancreas.

In the 2 remaining patients angiography did demonstrate the presence of a tumor. Patient A.S. (Fig. 4B) who had an angiographically demonstrated tumor in the tail of the pancreas had on TPVS elevated IRI concentrations in the midsplenic vein, inferior mesenteric vein (IMV), posterior superior pancreaticoduodenal (PSPDV), and the dorsal pancreatic vein, suggestive of a multicentric or diffuse process. This patient had undergone pancreatic surgery 1 yr earlier for hyperinsulinism with the enucleation of a single adenoma from the tail of the pancreas. At surgery this time, only the angiographically demonstrable tumor was palpable and frozen section examination of adjacent pancreas was "normal." Because of the demonstration by TPVS of non-localized disease, enucleation of the tumor was not attempted and a distal $2 / 3$ pancreatectomy was done. Histologic examination 
confirmed the presence of a single, lobulated adenoma and demonstrated associated diffuse islet cell hyperplasia.

Patient S.P., who presented with fasting hypoglycemia and hyperinsulinemia, had a large tumor ( $32 \mathrm{~g}$ ) of the head of the pancreas which was easily demonstrated angiographically. The highest insulin concentrations were found in the proximal superior mesenteric vein at or near the confluence with the splenic vein (Fig. 5A). High values of SRIF-LI were found in a distribution similar to that of insulin (Fig. 5B) suggesting that the tumor produced SRIF-LI as well.

None of the 9 patients has had recurrence of symptoms of organic hyperinsulinism. One patient (A.W.) is an insulin-requiring diabetic as a result of extensive resection of the pancreas.

In the six cases with small single adenomata, elevated concentrations of IRI were not always found exclusively in close proximity to the tumor. The highest concentration of insulin was found in the distal splenic vein in patient (A.B.) with a tumor in the tail of the pancreas (Fig. 2E). Elevated concentrations

\section{A INSULIN S.P. 23, Female}

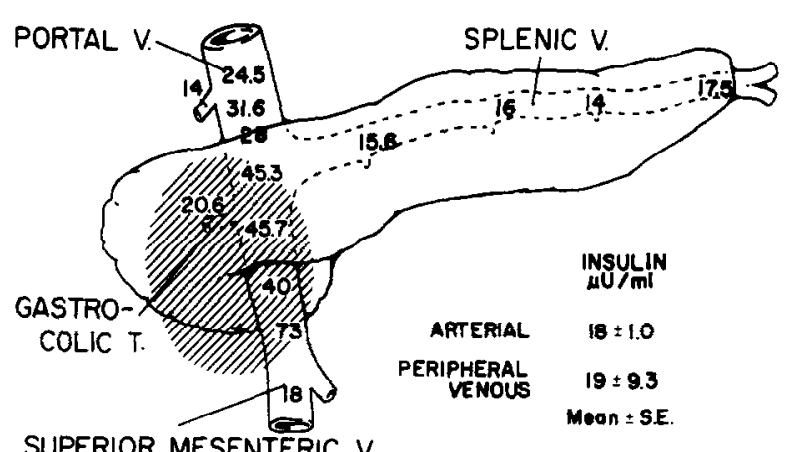

B SRIF-LI

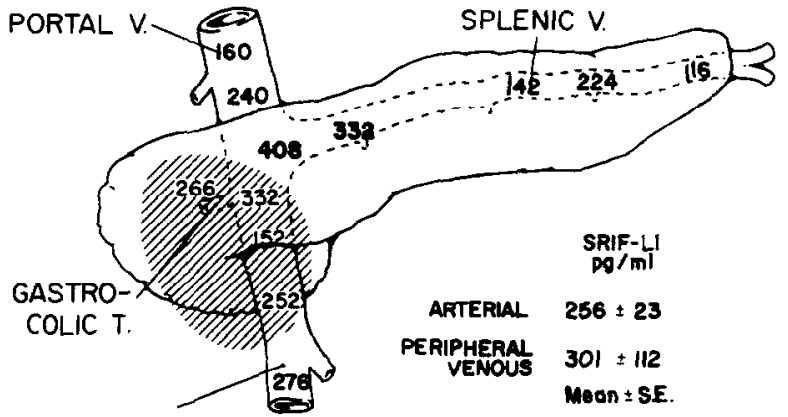

\section{SUPERIOR MESENTERIC V.}

Fig. 5. Schematic representation of pancreas and portalvenous system in a 23-yr-old female (SP) with a 10-yr history of symptoms of hypoglycemia. Angiography had located a large hypervascular tumor in head of the pancreas. Elevated levels of both insulin and SRIF-LI from the venous drainage of the head of the pancreas suggests that the tumor produced both hormones.

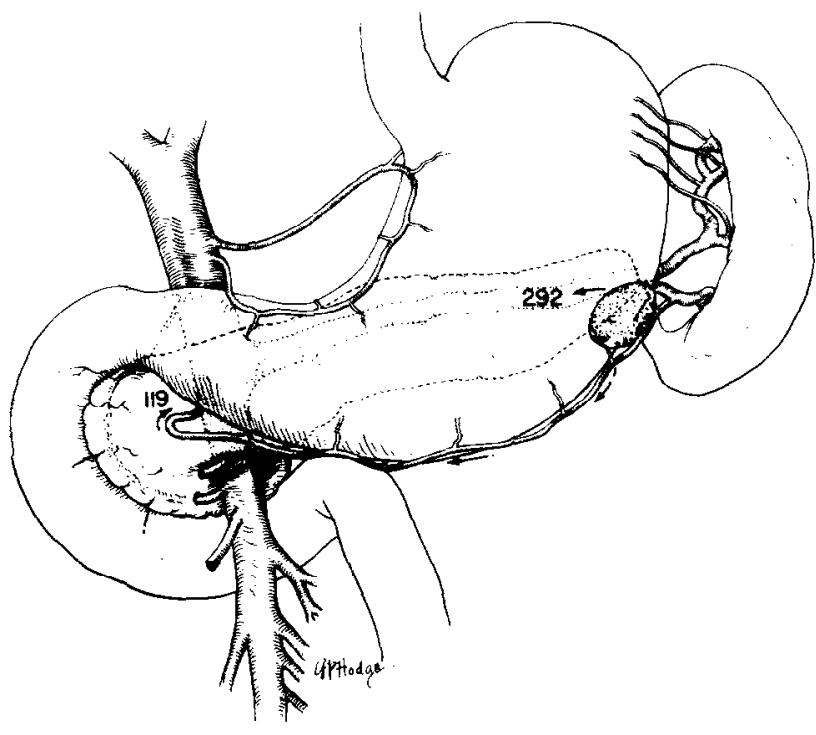

Fig. 6. Venous drainage into the gastroepiploic vein from an insulinoma located in the tail of the pancreas explaining the finding of elevated level $(119 \mu \mathrm{U} / \mathrm{ml})$ of insulin at the unexpected location remote from the tumor site (Fig. 2E).

were also found in the proximal splenic vein and in the gastrocolic trunk. A venous communication between the tail of the pancreas and the superior mesenteric vein via the gastroepiploic veins was visualized at surgery (Fig. 6). Patient N.H. had a tumor in the body of the pancreas. The highest concentration of insulin was found just distal to the tumor location in the splenic vein. However, there was also a lesser elevation proximal to this site. Direct drainage of a tumor located in the neck of the pancreas into the portal vein could be demonstrated at surgery in patient R.S. (Fig. 7). Duplicate sampling from the same site (Table 3) in the portal venous system at different times occasionally gave differing IRI concentrations.

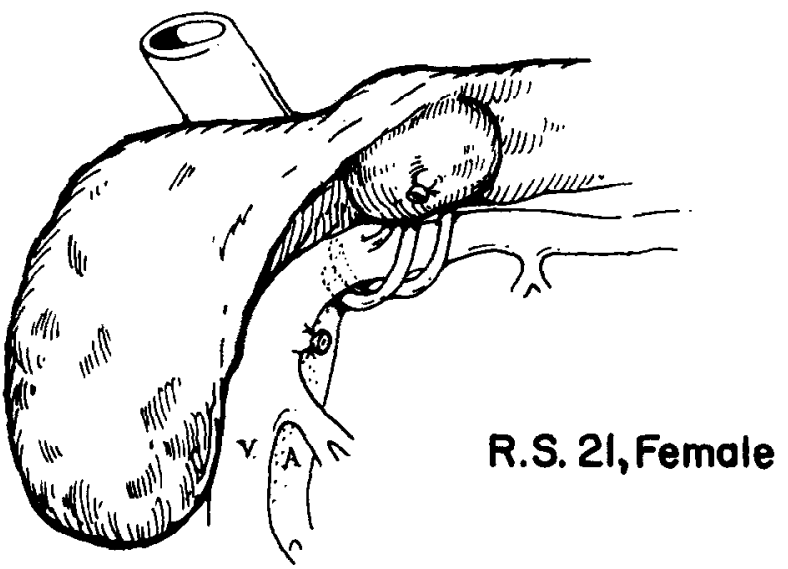

Fig. 7. Demonstration at operation of a tumor in the neck of the pancreas with direct venous communication into the proximal portal vein. The high insulin concentrations in the proximal portal vein (R.S. Fig. 2D) may be misinterpreted as coming from a tumor in the head of the pancreas. 
Tabie 3. Examples of Differences in Portal Venous IRI Concentrations with Non-Simultaneous Sampling at the Same Site

\begin{tabular}{cccccc}
$\begin{array}{c}\text { Patient } \\
\text { Site }\end{array}$ & $\begin{array}{c}\text { NH } \\
\text { Mid } \\
\text { Portal }\end{array}$ & $\begin{array}{c}\text { RS } \\
\text { Mid } \\
\text { Portal }\end{array}$ & $\begin{array}{c}\text { SP } \\
\text { Mid } \\
\text { SMV }\end{array}$ & $\begin{array}{c}\text { AB } \\
\text { Gastrocolic } \\
\text { Trunk }\end{array}$ & $\begin{array}{c}\text { DS } \\
\text { Distal } \\
\text { Splenic V. }\end{array}$ \\
\hline Sample 1 & 62 & 152 & 40 & 91 & 30 \\
Sample 2 & 79 & 231 & 73 & 119 & 55 \\
\hline
\end{tabular}

In the 5 patients with single insulinomas, the mean concentrations of IG, IRG, hPP and SRIF-LI in the portal venous system are given in Table 4 along with the portal/systemic gradients. Patients A.W. and A.S. were excluded from this analysis because of their diffuse disease process which may be associated with other islet hormone abnormalities. Patient S.P. and A.Sa. were excluded because their tumors produced more than one hormone, a situation that may affect the secretory patterns of other hormones. The highest concentration and significant gradient of gastrin was found in the gastrocolic trunk; hPP gradient was greatest in the proximal portal vein; SRIF-LI gradient was greatest in the superior-mesenteric vein and gastroepiploic vein; IRG concentrations were similar at all locations with positive gradients throughout the portal venous system.

\section{DISCUSSION}

We have carried out transhepatic portal venous sampling to; (1) localize insulin-producing tumors and to help in differentiating single tumors from diffuse disease (nesideoblastosis and hyperplasia with adenoma) and (2) determine concentrations of other gut/ pancreatic hormones in the portal venous system.

We have studied 6 patients with small single adenomas that were not angiographically demonstrable and have confirmed the findings of others ${ }^{6-10}$ that even small tumors $(<1 \mathrm{~cm})$ can be localized preoperatively using the technique of TPVS. In 5 of these 6 patients, preoperative localization by TPVS was helpful to the surgeon in directing him to the tumor site since it was not easily palpable at initial exploration.

Two patients with diffuse pancreatic disease were also studied. One, A.S., had a single lobulated tumor demonstrated angiographically preoperatively, however, the history of prior removal of another ademona suggested the presence of multiple adenomatosis. At surgery, a single tumor was found, associated with diffuse hyperplasia. The other patient, A.W., had in retrospect a history suggestive of hypoglycemia dating from one year of age, however, biochemical hypoglycemia was not recognized until age $17 \mathrm{yr}$ (Table 1). Nesideoblastosis was found at operation. Both of these patients had multiple areas of elevated IRI concentrations suggesting that: (1) both these processes are non-homogeneous, and (2) TPVS cannot differentiate nesideoblastosis from hyperplasia with adenoma. Multifocal, nonhomogeneous secretion of insulin was found in a patient with hyperplasia without adenomata by Ingemansson. ${ }^{28}$ Thus, nesideoblastosis and hyperplasia with and without adenomata cannot be distinguished by the hormonal profile in TPVS.

The interpretation of data obtained during these and similar studies requires an appreciation of the complexity and variability of the venous drainage of the pancreas and proximal gut. We have demonstrated that a tumor in the tail of the pancreas can drain into the gastroepiploic vein (A.B.) resulting in high hormone levels remote from the actual tumor site (Fig. 6 ). The high insulin concentration noted near the confluence of the splenic and superior mesenteric veins in the same patient (Fig. 2E) may be related to tumor drainage through the short gastric veins into the coronary vein which enters at that point. The findings of a moderately elevated concentration of insulin in the splenic vein proximal to the tumor in patient N.H. may relate to variabilities of venous admixture, or catheter placement. Such findings may present difficulties in differentiation of patients with single tumors from those with diffuse disease who have elevated concentrations found at multiple remote sites such as patient A.S. whose elevated IRI concentrations in the PSPDV is not compatible with collateral drainage from a tumor in the body or tail of the pancreas.

A tumor of the head of the pancreas (E.V.) could be identified by high insulin levels in the area of drainage into the superior pancreaticoduodenal vein, while one in the neck of the pancreas (R.S.) drained into the proximal portal vein close to the junction of the superior mesenteric and splenic veins. A tumor of the body of the pancreas (N.H.) drained into the midsplenic vein. A maximum insulin concentration as low as $64 \mu \mathrm{U} / \mathrm{ml}$ or a tumor site-arterial gradient of 39 $\mu \mathrm{U} / \mathrm{ml}$ may be sufficient to localize a tumor. Values as low as $41^{9}$ and $62 \mu \mathrm{U} / \mathrm{ml}^{8}$ have been reported.

Repeated sampling at the same location at different times can yield variable hormone concentrations. This variability may be due to a minor error in estimating catheter location, laminar flow of blood within major veins, or pulsatile hormone secretion. In none of our cases did this problem result in error of localization however. multiple site samplings and repetitive samplings at different times may help in identifying spuriously elevated or suppressed levels.

Two patients had evidence on TPVS of multiple hormone production by their tumors. The normal peripheral glucagon concentrations, even though there was excessive glucagon output by the tumor in patient A.Sa., explain the absence of the usual stigmata of the 
glucagonoma syndrome such as migratory necrolytic erythema. The other patient (S.P.) had a large tumor, but relatively low fasting IRI concentrations. The finding of excessive SRIF secretion from the tumor may explain why IRI concentrations were not higher and hypoglycemic symptoms were not more severe. That there were none of the features of somatostatin excess-steatorrhea, achlorhydria or gall bladder disease, ${ }^{13-19}$ may be related to the relatively low (400 $\mathrm{pg} / \mathrm{ml}$ ) circulating SRIF concentrations. In patients with symptomatic somatostatinomas, peripheral venous concentrations were generally $>1000 \mathrm{pg} / \mathrm{ml}^{13-19}$

The use of TPVS for the evaluation of patients with organic hyperinsulinism is indicated only after a definitive diagnosis has been made using the appropriate clinical and laboratory tests, and only in those patients where a tumor has not been located angiographically or when a diffuse process is suspected. Patients with recurrent hypoglycemia after removal of an insulinoma, patients with multiple endocrine neoplasia Type I (MEN-I) or with a family history of MEN-I often have diffuse pancreatic disease and even if a single adenoma is demonstrated angiographically, TPVS is indicated before operation. The use of TPVS in patients with a clinical presentation of a single insulinoma demonstrable angiographically is not justified at this time as the procedure is not innocuous, although we encountered no major complications in the nine patients studied.

Most of these patients complained of severe right flank and epigastric pain during the procedure despite narcotic analgesia and sedation. This pain persisted for 1-2 days, but rarely required further analgesia after the first 4-6 hr. Seven of the nine patients were ambulatory and could be discharged $24 \mathrm{hr}$ after the procedure was completed, though two remained hospitalized for further testing. One patient (R.S.) had a decrease in hematocrit following the procedure, probably related to bleeding into the thigh at the site of arterial puncture, but blood loss from the transhepatic procedure cannot be entirely ruled out since stools, while grossly normal, were positive for occult blood. Another patient (A.W.) had flank tenderness, rebound tenderness, and an increase in abdominal girth, which resolved spontaneously after $72 \mathrm{hr}$.

Immunohistochemical studies have determined that gut/pancreatic hormones are not distributed evenly throughout the entire pancreas. By studying the concentrations of hormones other than insulin in the gut/pancreatic venous cffluent of paticnts with single small insulinomas we have been able to obtain an estimation of the maximum concentrations and portal-systemic gradients of these hormones in the unaffected pancreas, and have also found this distribu-

tion to be non-homogeneous for gastrin, hPP and SRIF-LI, providing functional confirmation of the previous a natomical findings.

The maximum concentration of gastrin in the gastrocolic trunk is compatible with its origin from the gastric antrum and the absence of a significant gradient between the concentrations in the pancreatic venous effluent and the systemic circulation supports the observation that there are no gastrin cells in the adult human pancreas and that heptadecapeptide gastrin is not inactivated by passage through the liver. ${ }^{41,42}$

The glucagon concentrations measured with this antiserum reflect "pancreatic" IRG. There is only $2 \%-5 \%$ cross-reactivity with GLI. The levels in the peripheral venous system are lower than those reported in healthy subjects using Unger's $30 \mathrm{~K}$ antiserum and the portal vein/arterial gradient of $31 \%$ (Table 4) is acceptable for the known hepatic extraction of glucagon. ${ }^{43}$ The positive gradients found in the superior mesenteric and gastrocolic trunk suggest secretion of a "pancreatic" type glucagon produced by the gut in humans and is in keeping with persistence of IRG in the circulation after total pancreatectomy in man. ${ }^{44}$

The hPP concentrations in the portal vein were $30 \%$ greater than in the peripheral circulation. A positive portal-peripheral venous concentration-difference indicating hepatic extraction of PP has been demonstrated, ${ }^{45,46,47}$ but not confirmed. ${ }^{48}$ The highly selective elevation of hPP levels only in the distal portal vein, could account for the failure ${ }^{48}$ to find a gradient, since

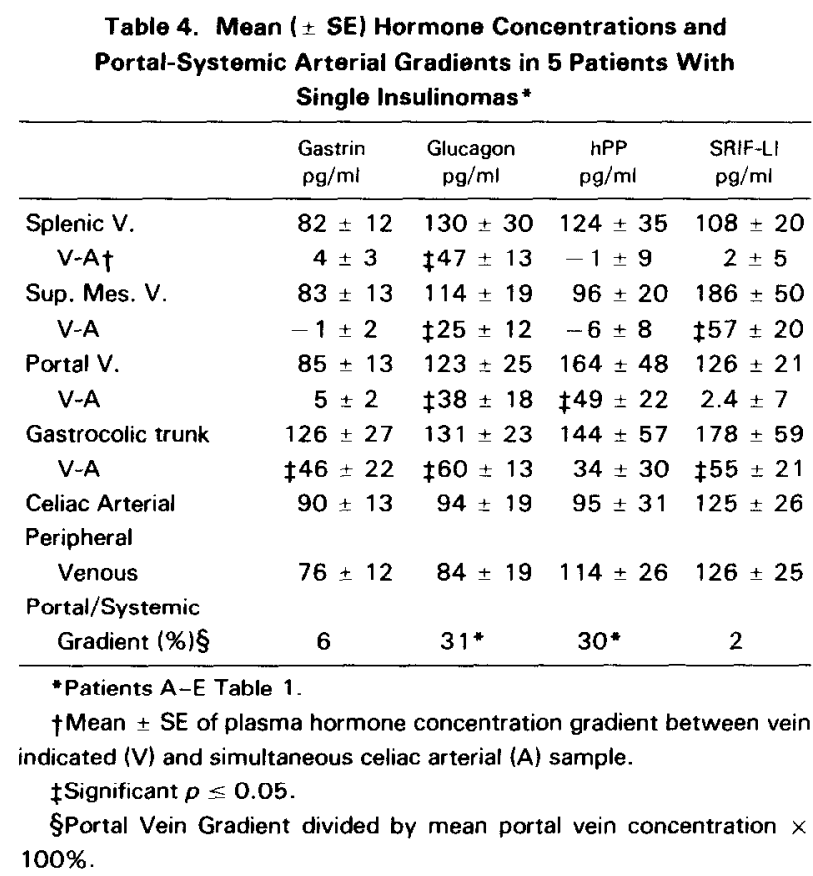


samples may have been taken at too proximal a site. The higher levels in the portal vein, close to the liver, adjacent to the posterior superior pancreaticoduodenal vein are in keeping with the anatomic localization of most of the PP cells in a separate lobe in the head of the pancreas. ${ }^{29} .30$

The fasting SRIF-LI concentrations in the peripheral vein and celiac artery are similar to those reported in healthy subjects ${ }^{38}$ when unextracted plasma is used, but may be higher than levels found in extracted plasma. The greatest concentrations is the gastrocolic trunk and superior mesenteric veins suggest that in man most of the SRIF-LI secreted into the portal venous system derives from the proximal small gut corresponding with the greatest tissue levels found by extraction of the gut and pancreas in dog and man. ${ }^{49}$ These data will be necessary in the interpretation of future studies done for localization of tumors producing these hormones.

In our studies we have obtained celiac artery and/or peripheral venous samples simultaneously with portal samples. While these values were not needed in any of our cases to adequately localize the tumors, calculating portal-systemic gradients of SRIF-LI, glucagon, and hPP can be expected to add to the accuracy of localizing maximum concentrations and gradients by avoiding apparent differences due to rapid oscillations of hormone levels.

In summary, we have localized by TPVS small angiographically-negative insulinomas in 6 patients. Some problems in interpretations of portal venous insulin concentrations are discussed. We have demonstrated the non-homogeneous pattern of IRI secretion in a patient with nesideoblastosis and one with islet hyperplasia and adenoma, making it impossible to distinguish these two entities by this procedure. We have demonstrated glucagon production by an insulinoma in a patient with normal peripheral plasma concentration of glucagon and SRIF production by a large insulinoma in a patient with normal peripheral plasma SRIF concentrations. The procedure appears to be relatively safe albeit painful, and can be recommended for those patients with proven organic hyperinsulinism but negative pancreatic angiograms or those with recurrent hypoglycemia due to multiple tumors or MEN-I. We have also delineated some of the complexities of the pancreatic venous drainage and provided new information on the concentrations and gradients of IRG, hPP, SRIF-I.I and gastrin in the portal venous system in man, which may be helpful in the interpretation of future studies.

\section{NOTE ADOED IN PROOF}

Since submission of this manuscript we have localized by TPVS two more single insulinomas which were not demonstrable angiographically, each located in the uncinate process of the pancreas. Concentrations of insulin were highest in the superior mesenteric vein; in one patient opposite the entry of the gastrocolic trunk and the posterior inferior pancreatico-duodenal vein and in the other patient half way between the entry of the gastrocolic trunk and the confluence of the superior mesenteric vein and splenic vein. In both patients preoperative localization of TPVS was most helpful to the surgeon as the tumors became palpable only after mobilization and dissection of the uncinate process.

\section{REFERENCES}

1. Ciray RK, Roseh J, Grollman JH: Artcriography in the Diagnosis of Islet Cell Tumors. Radiology 97:39-44, 1970

2. Robins JM, Bookstein JJ, Oberman HA and Fajans SS: Selective Arteriography in Localizing Islet Cell Tumors of the Pancreas. Radiology 106:525-528, 1973

3. Fulton RE, Shecdy PF, Mclllrath DC, et al: Preoperative Angiographic Localization of Insulin Producing Tumors of the Pancreas. Am J Roentgenol 123:367-377, 1975

4. Holmes JH, Findley L. Frank B: Diagnosis of Pancreatic Pathology Using Ultrasound. Trans Am Clin Clinicopathol Assoc $85: 224,1973$

5. Stefanini P, Carboni $M$, Patrassi $N$, et al: Beta Islet Cell Tumors of the Pancreas: Results of a Study of 1067 Cases. Surgery $75: 597-609,1974$

6. Ingemansson S, Lunderquist A, Lundquist I, et al: Portal and Pancreatic Vein Cathetcrization with Radioimmunologic Determination of Insulin. Surg Gynecol Obstet 141:705-711, 1975

7. Turner RC, Lee ECG, Morris PJ, et al: Localization of Insulinomas. Lancet 1:515-518,1978

8. Millan VG, Urosa CL. Molitch ME et al: Localization of Occult Insulinoma by Superselective Pancreatic Venous Sampling for Insulin Assay Through Percutaneous Transhepatic Catheterization. Diabetes 28:249-251, 1979

9. Mitty HA. Efremidis S, Westkin MG, et al: Localization of
Insulinomas by Radioimmunoassay of Blood Oblained by the Transportal Route. J Clin Endocrinol Metab 48:1035-1037, 1979

10. Lunderquist A, Eriksson M. Ingemansson $S$, et al: Selective Pancreatic Vein Catheterization for Hormone Assay in Endocrine Tumors of the Pancreas. Cardiovasc Radiol 1:117-124, 1978

11. Zollinger RM, Ellison EH: Primary Peptic Ulcerations of the Jejunum Associated with Islet Cell Tumors of the Pancreas. Ann Surg 142:709 723, 1955

12. Holst $S S$, Helland $S$, Ingemannson $S$, et al: Functional Studies in Patients with Glucagonoma Syndrome. Diabetologia 17:151-156, 1979

13. Krejs GJ, Orci L, Conlon M, et al: Somatostatinoma Syndrome (Biochemical, Morphologic and Clinical Features). N Eng J Med 301:285-292, 1979

14. I arsson LI, Hirsch MA, Holst J, et al: Pancreatic Somatostatinoma Clinical Features and Physiologic Implications. Lancet $1: 666-668,1977$

15. Ganda OP. Weir GC, Soeidner JS, et al: A SomatostatinContaining Tumor of the Endocrine Pancreas. N Eng I Med 296:963-967, 1977

16. Unger RH: Somatostatinoma. N Eng J Med 296:998-1000, 1977

17. Kovaes K. Horvath E, Ezrin C, et al: Immunoreactive 
Somatostatin in Pancreatic Islet Cell Carcinoma Accompanied by Ectopic ACTH Syndrome. Lancet 1:1365-1 366, 1977

18. deNutte N, Somers G, Gepts W, et al: Pancreatic Hormone Release in Tumor Associated Hypersomatostatinemia. Diabetologia 15:227, 1978

19. Gahniche JP, Conlin R, DuBois PM, et al: Calcitonium Secretion by a Pancreatic Somatostatinoma. N Eng J Med 299:1252, 1978

20. Larsson LI, Schwartz T, Lundquist G, ef al: Pancreatic Polypeptide in Pancreatic Endocrine Tumors, Possible Implication in Watery Diarrhea Syndrome. Am J Path 85:675-682, 1976

21. Bloom SR, Polak JM, Pearse AGE: Vasoactive Intestinal Polypeptide and Watery Diarrhea Syndrome. Lancet 2:14-16, 1973

22. Said SI, Faloona GR: Elevated Plasma and Tissue Levels of Vasoactive Intestinal Polypeptide in the Watery Diarrhea Syndrome Due to Pancreatic, Bronchogenic and Other Tumors. N Eng J Med 293:155-160, 1975

23. Larsson L-I, Grimelius L, Hakanson R, et al: Tumors Producing Several Peptide Hormones. Am J Pathol 79:271-284, 1975

24. Frantz VK: Adenomatosis of islet cells, with hyperinsulinism. Ann Surg 119:824-844, 1944

25. Ingemansson $S$, Larsson Ll, Lunderquist $A$, et al: Pancreatic Vein Catheterization with Gastrin Assay in Normal Patients and in Patients with the Zollinger-Ellison Syndrome. Am J Surg 134:558563,1977

26. Burcharth F, Stage JG, Stadil F, et al: Localization of Gastrinomas by Transhepatic Portal Catherization and Gastrin Assay. Gastroenterol 77:444-450, 1979

27. Ingemansson S, Holst J, Larsson LI, et al: Localization of Glucagonomas by Catheterization of the Pancreatic Veins and with Glucagon Assay. Surg Gyn Obst 145:509-516, 1977

28. Ingemansson S, Holst J, Larsson LI, et al: Islet Cell Hyperplasia Localized by Pancreatic Vein Catheterization and Insulin Radioimmunoassay. Am J Surg 133:643-645, 1977

29. Erlandsen SL, Hegre OD, Parsons JA, et al: Pancreatic Islet Cell Hormones: Distribution of Cell Types in the Islet and the Fvidence for the Presence of Somatostatin and Gastrin Within the D Cell. J Histochem Cytochem 24:883-897, 1976

30. Orci L, Malaisse-Lagae F, Baetes D, et al: Pancreatinpolypeptide Rich Regions in Human Pancreas. Lancet 2:1200-1201, 1978

31. Malaisse-Lagae F, Stefan Y, Cox I, et al: Identification of a Lobe in the Adult Human Pancreas Rich in Pancreatic Pelypeptide. Diabetologia 17:361-366, 1979

32. Fajans SS, Floyd JC Jr, Vij SK: Differential Diagnosis of Spontaneous Hypoglycemia, in Kryston LJ and Shaw RA (eds): Endocrinology and Diabetes. New York, Grune and Stratton, Inc., 1975, pp 453-472
33. Fajans SS, Floyd JC Jr: Diagnosis and Medical Management of Insulinomas. Ann Rev Med 30:313-329, 1979

34. Hayashi M, Floyd JC. Jr, Pek S, et al: Insulin, Proinsulin, Glucagon and Gastrin in Pancreatic Tumors and in Plasma of Patients with Organic Hyperinsulinism. J Clin Endo Metab 44:681694, 1977

35. Vinik AI, Grant BJ, Novis B: Gastrins in Human Antrum, Duodenum, and Peripheral Circulation. S Afr Med J 49:255-257. 1975

36. Pek S, Fajans SS, Floyd JC Jr, et al: Failure of Sulfonylureas to Suppress Plasma Glucagon in Man. Diabetes 21:216-223, 1972

37. Floyd JC Jr, Fajans SS, Pck S, et al: A Newly Recognized Pancreatic Polypeptide: Plasma Levels in Health and Disease. Recent Prog Horm Res 33:519-569, 1977

38. Vinik Al, Levitt N, Pimstone BL, et al: Peripheral Plasma Somatostatin-Like Immunoreactive and Responses to InsulinHypoglycemia and a mixed Meal in Healthy Subjects and in Non-Insulin-Dependent Maturity-Onset Diabetics. I Clin Endocrinol Metab 52:330-337, 1981

39. Slein MW: Methods of Enzymatic Analyses, in Bergmeyer H (ed). New York, Academic Press, 1963, p 117

40. Bondar RJ, Mead DC: Evaluation of Glucose-6-Phosphate Dehydrogenase from Leuconostoc Mesenteroids in the Hexokinase Method for Determining Glucose in Serum. Clin Chem 20:586-590, 1974

41. Sacks H, Grant BJ, Vinik AI: Metabolism of Synthetic Human Heptadecapeptide Gastrin by the Isolated Perfused Rat Livers. S Afr Med J 53:249-251, 1978

42. Vinik AI, Hickman R, Grant BJ: Endogenous and Exogenous Heptadecapeptide Gastrin Transport Across the Pig Liver. S Afr Med J 53:759-765, 1978

43. Blackard WG, Nelson NC, Andrews SS: Portal and Peripheral Vein Immunoreactive Glucagon Concentrations After Arginine or Glucose Infusion. Diabetes 23:199-202, 1974

44. Botha JL, Vinik Al, Child PT, et al: Pancreatic Glucagon Like Immunoreactivity in a Pancreatectomized Patient. Horm Metab Res 9:199-205, 1977

45. Loo SW, Hirsch HJ, Gabbay KH: Human Pancreatic Polypeptide, Portal Peripheral Gradient in Man. Diabetes 26:407, 1977

46. Sive AA, Vinik AI, Hickman-Van Hoorn R, et al: Secretory Responses of Pancreatic Polypeptide in Man and Pigs. Scand J Gastroenterol 13 (Suppl 49): 167, 1978

47. Floyd JC Jr: Human Pancreatic Polypeptide. Clinics of Endocrinology 8:379-399, 1979

48. Boden G, Master RWP, Owen OE: Hepatic and Renal Extraction of Endogenous Human Pancreatic Polypeptide. J Gastroenterol 13 (Suppl 49):28, 1978

49. McIntosh C. Arnold R, Bothe E, et al: Gastrointestinal Somatostatin in Man and Dog. Metabolism 27:1317-1320, 1978 